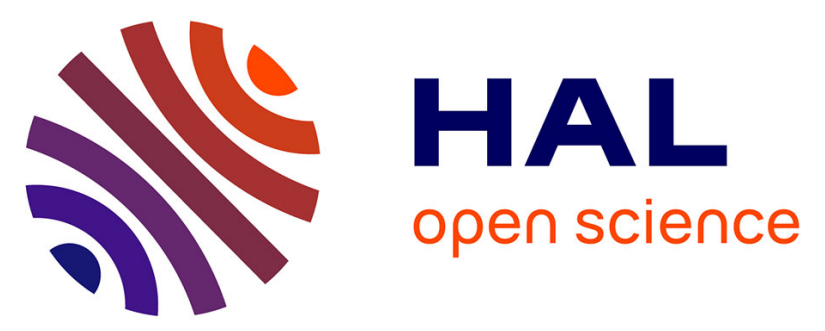

\title{
Asymmetric competition, ontogenetic growth and size inequality drive the difference in productivity between two-strata and one-stratum forest stands
}

\author{
Thomas Cordonnier, C. Smadi, Georges Kunstler, Benoît Courbaud
}

\section{- To cite this version:}

Thomas Cordonnier, C. Smadi, Georges Kunstler, Benoît Courbaud. Asymmetric competition, ontogenetic growth and size inequality drive the difference in productivity between twostrata and one-stratum forest stands. Theoretical Population Biology, 2019, 130, pp.83-93. 10.1016/j.tpb.2019.07.001 . hal-02609938

\section{HAL Id: hal-02609938 \\ https://hal.inrae.fr/hal-02609938}

Submitted on 21 Dec 2021

HAL is a multi-disciplinary open access archive for the deposit and dissemination of scientific research documents, whether they are published or not. The documents may come from teaching and research institutions in France or abroad, or from public or private research centers.
L'archive ouverte pluridisciplinaire HAL, est destinée au dépôt et à la diffusion de documents scientifiques de niveau recherche, publiés ou non, émanant des établissements d'enseignement et de recherche français ou étrangers, des laboratoires publics ou privés.

\section{(ㄷ)(1) $\$$}

Distributed under a Creative Commons Attribution - NonCommerciall 4.0 International 
1 Asymmetric competition, ontogenetic growth and size inequality

\title{
drive the difference in productivity between two-strata and one-stratum forest stands
}

\author{
Thomas Cordonnier ${ }^{\mathrm{a}, *}$, Charline Smadi ${ }^{\mathrm{b}, \mathrm{c}}$, Georges Kunstler ${ }^{\mathrm{a}}$, Benoît Courbaud ${ }^{\mathrm{a}}$ \\ ${ }^{a}$ Univ. Grenoble Alpes, Irstea, LESSEM, 38000 Grenoble, France. \\ ${ }^{b}$ Irstea, UR LISC, Laboratoire d'Ingénierie pour les Systèmes Complexes, 9 avenue Blaise Pascal-CS \\ 20085, 63178 Aubière, France. \\ ${ }^{c}$ Complex Systems Institute of Paris Ile-de-France, 113 rue Nationale, Paris, France.
}

\section{Abstract}

Size inequality has been considered a key feature of plant population structure with impacts on ecosystem functions. In forest ecosystems, studies examining the relationship between tree size inequality and stand productivity have produced mixed outcomes. These studies found positive, neutral or negative relationships and discussed how this could be influenced by competition for light between trees (e.g. light interception efficiency), but far less attention has been paid to the role played by tree ontogenetic growth. In this article, we present a simple mathematical model that predicts the basal area growth of a two-strata stand as a function of tree basal areas and asymmetric competition. Comparing the growth of this stand to the growth of a spatially homogeneous one-stratum stand and a spatially heterogeneous one-stratum stand, we show that higher growth of the two-strata stand is achieved for concave shape, increasing functions of ontogenetic growth and for low intensities of absolute size-asymmetric competition. We also demonstrate that the difference in growth between the two-strata stand and the one-stratum stands depends on tree size inequality, mean tree basal area and total basal area in the two-strata stand. We finally found that the relationships between tree size inequality and productivity can vary from positive to negative and even non-

\footnotetext{
*Corresponding author

Email addresses: thomas.cordonnier@irstea.fr (Thomas Cordonnier), charline.smadi@irstea.fr (Charline Smadi), georges.kunstler@irstea.fr (Georges Kunstler), benoit.courbaud@irstea.fr (Benoît Courbaud)
} 
monotonous. However, we highlight that negative relationships may be more frequent. As a conclusion, our results indicate that ontogenetic growth can have a major impact on the form and the magnitude of the size inequality-productivity relationship. Keywords: forest structure, tree basal area increment, theoretical model, competition, stand productivity

\section{Introduction}

Understanding how structural complexity influences ecosystems' dynamics and functioning is a central ecological question because human activities tend to homogenise natural systems (e.g. Messier et al., 2015). With the biodiversity crisis, this topic has been mainly explored from the point of view of species diversity loss (Cardinale et al., 2012) but other aspects of structural complexity can also be crucial. For instance in forests, size inequality (i.e. a measure of size differentiation or size hierarchy between trees in a stand) has been considered a key component of structural complexity with impacts on forest dynamics (Courbaud et al., 2015), ecosystem processes (Forrester and Bauhus, 2016) and associated biodiversity (McElhinny et al., 2005). Because of this, several forest management systems such as gap-based management (Kern et al., 2017) or nature-based management (Brang et al., 2014) have been developed with the goal of fostering size inequality. Since productivity is an essential feature of forest functioning and a major driver of forest management planning (Villa et al., 2013; Bontemps and Bouriaud, 2014), the effect of size inequality on productivity (in basal area, volume or biomass) has received increased interest in the last few decades.

Studies examining the relationship between size inequality and productivity (stand growth in terms of basal area, volume or biomass) have produced contradictory results. On the one hand some studies using field observations, experiments or individual-based models reported negative or neutral relationships between size inequality (measured with various indices such as the Gini index, the coefficient of variation or the Shannon 
entropy index) and stand productivity (Liang et al., 2007; Bourdier et al., 2016; Ryan et al., 2010; Long and Shaw, 2010; Soares et al., 2016; Bohn and Huth, 2017). On the other hand, other studies found positive relationships in mixed stands (Danescu et al., 2016; Silva Pedro et al., 2017). A striking example of these contradictions is the recent study of Zeller et al. (2018) based on national forest inventory plots, which showed a negative size inequality effect in Germany but a positive effect in the USA. Such contradictory results can be explained by the fact that studies present several major differences concerning the ecological context considered, the surface of the plots, the temporal scale, the size inequality index selected and the factors controlled for stand structure. Moreover, correlations between size inequality and other stand attributes, such as stand development stage, density and species richness, can be difficult to control in observational studies. If we want to progress on this question and make sense of these contradictory results we need to build theoretical predictions about the variables and mechanisms influencing the effects of size inequality on productivity.

Competition is one of the key processes influencing productivity in plant populations and communities (Connell, 1983). Size inequality has been related to size-asymmetric competition (Damgaard and Weiner, 2000; Cordonnier and Kunstler, 2015), a type of competitive interaction where large plants have a disproportionate competitive advantage over small plants (Weiner, 1990). Competition for light is presented as a classic mechanism leading to size-asymmetric competition (Schwinning and Weiner, 1998). Discussions on the effect of size inequality on productivity have thus focused on mechanisms related to competition for light (e.g. Bourdier et al., 2016; Binkley et al., 2010). In addition to competition, ontogenetic growth, i.e. the change of growth with tree age or tree size (West et al., 2001), might be crucial but has received far less attention. For instance, a recent study on plants has stressed the need to control for the ontogenetic growth function in order to avoid misinterpretations about the effect of asymmetric competition on the evolution of population size inequality (Rasmussen and Weiner, 2017). 
In forest ecosystems, absolute tree growth generally increases with size (Stephenson et al., 2014), but other forms (e.g. skewed unimodal) have been reported (e.g. Wykoff, 1990). These ontogenetic changes in growth are likely to influence the effect of size inequality on productivity depending on the shape of the ontogenetic growth function and the mean size of the stand. Because of the lack of theoretical developments we have no expectations about the relative role of competition and the ontogenetic effect on size inequality-productivity relationships. Although highly useful to investigate size-inequality relationships through a dynamic perspective, the few existing simulation studies (Silva Pedro et al., 2017; Bohn and Huth, 2017; Bourdier et al., 2016) use complex individual-based models in which disentangling the effects of competition and ontogeny is difficult.

In this article, we present a simple mathematical model that predicts the basal area growth of a two-strata stand. This model takes into account the competition between trees of the same stratum and between trees of different strata to represent different intensities of size-asymmetric competition of the upper stratum and types of size-asymmetric competition of the lower stratum: absolute (trees in the lower stratum have no influence on trees in the upper stratum), partial (trees in the lower stratum have less influence on trees in the upper stratum than on trees in the lower stratum) and relative (trees in the lower stratum have the same influence on all trees). In addition, the model explores various shapes of the ontogenetic growth function, while controlling for the mean tree basal area and the stand basal area. Using this model, we compared the basal area growth of a two-strata stand with a spatially homogeneous one-stratum stand. We also compared the basal area growth of the two-strata stand to the growth of a spatially heterogeneous one-stratum stand, which allowed us to remove the direct effect of ontogenetic growth on the size inequality-productivity relationship. Our objective was twofold: first to analyse the conditions that lead to higher productivity of the two-strata stand compared to one-stratum stands and second to identify parameter combinations 
leading to different relationships between size inequality and productivity. Our main hypothesis was that both ontogenetic growth and size-asymmetric competition have a major influence on the qualitative and quantitative behaviours of our system.

\section{The model}

\subsection{Stand with two strata (2-strata)}

Let us consider a stand with two main strata ( $u$ : upper, $l$ : lower). In a given stratum all trees share the same size, here individual basal area $\left(g_{u}\right.$ : upper, $g_{l}$ : lower; in $\left.m^{2}\right)$. We chose basal area as most empirical studies used this variable to deal with size growth at the individual scale. The following formulation can also work with other metrics such as tree diameter, tree volume or tree biomass. Here we need to specify how stand basal area or tree density is distributed between the two strata. Based on the frequent observation of J-shaped size distributions in natural forests, we consider the specific case where each stratum has the same basal area per hectare $G\left(G>0 ; m^{2} h a^{-1}\right)$ and thus different number of trees per hectare $\left(N_{u}\right.$ and $\left.N_{l}\right)$. We then define the annual basal area growth $\Delta g_{l}\left(m^{2} h a^{-1} y_{e a r^{-1}}\right)$ of a tree in the lower stratum as follows:

$$
\Delta g_{l}=a g_{l}^{b} e^{-c g_{l}} * e^{-\alpha\left(N_{l}-1\right) g_{l}} * e^{-\beta G} \approx a g_{l}^{b} e^{-c g_{l}} * e^{-(\alpha+\beta) G},
$$

where $a, b, c, \lambda, \beta$ are positive parameters. The first term, $a g_{l}^{b} e^{-c g_{l}}$, defines the ontogenetic effect on basal area growth of a tree without competition. This term depends on the size of the tree, here its basal area. The selected function defines a wide range of diameter growth patterns (positive concave, positive convex, skewed unimodal; Fig. 1) and has been used in several forest modelling studies (e.g. Wykoff, 1990; Pokharel and Dech, 2012; Cordonnier and Kunstler, 2015). The second term represents the reduction of growth due to the competition by trees of the same stratum $\left(e^{-\alpha G}\right)$ and by trees of the upper stratum $\left(e^{-\beta G}\right)$, respectively. The approximation $e^{\alpha g_{l}} \approx 1$ is applied because 

$\left.117 g_{u} / g_{l} \geq 2\right)$.

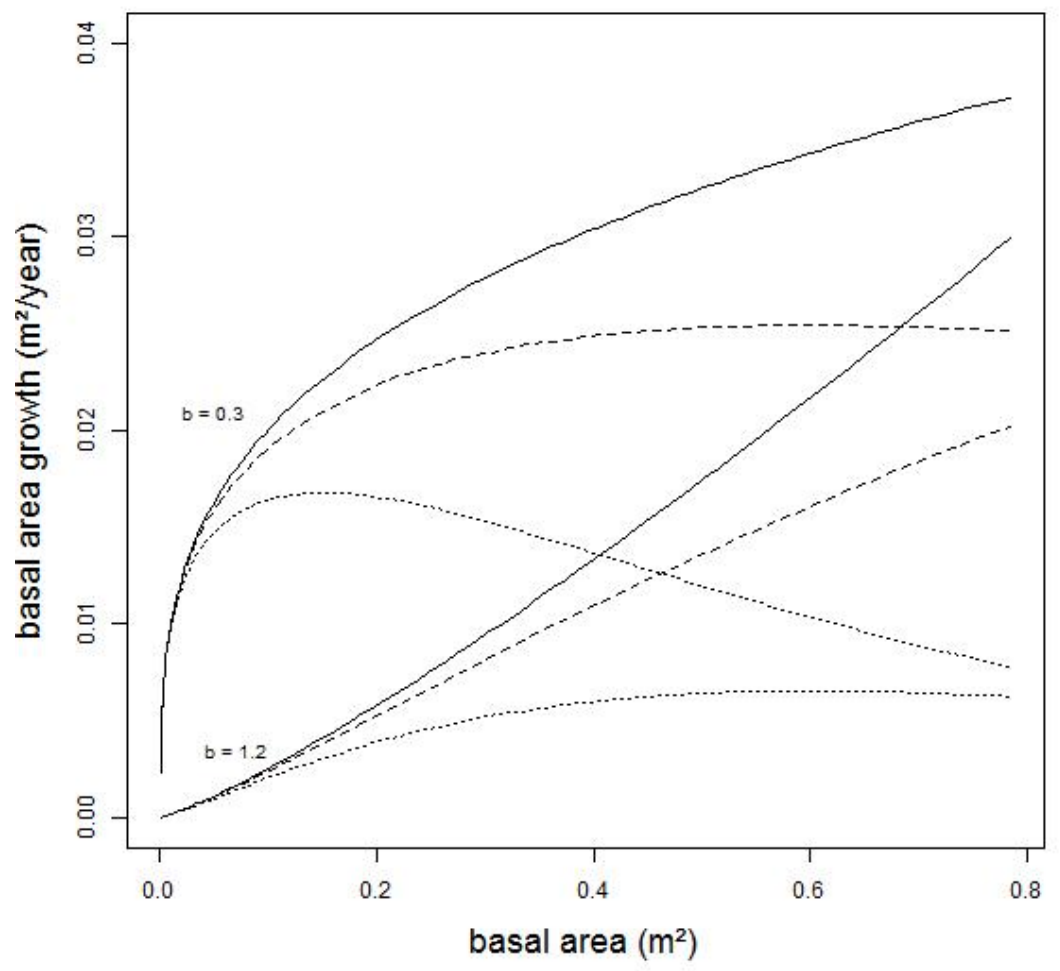

Figure 1: Basal area growth as a function of tree basal area for different values of parameters for the growth function $\Delta g=a g^{b} e^{-c g}$. Solid line: $c=0$, dashed line: $c=0.5$, dotted line: $c=2$.

Following the same reasoning, we can define the basal area growth of a tree belonging to the upper stratum: 


$$
\Delta g_{u}=a g_{u}^{b} e^{-c g_{u}} * e^{-(\alpha+\gamma) G},
$$

with $0 \leq \gamma \leq \alpha$, which means that a tree belonging to the lower stratum has an equal or lower effect on a tree in the upper stratum than on a tree in the same stratum. The term $e^{-\gamma G}$ represents the competitive effect of the lower stratum on trees in the upper stratum. This is related to the type of size-asymmetric competition. We assume here that the intra-stratum competition effect of a tree (parameter $\alpha$ ) is the same for the two strata. Summing all trees and the two strata, we obtain the total basal area growth of the stand $\left(m^{2} h a^{-1} y e a r^{-1}\right)$ :

$$
\Delta G_{1}=G\left(\frac{\Delta g_{l}}{g_{l}}+\frac{\Delta g_{u}}{g_{u}}\right)=G\left[g_{l}^{b-1} e^{-c g_{l}} e^{-(\alpha+\beta) G}+g_{u}^{b-1} e^{-c g_{u}} e^{-(\alpha+\gamma) G}\right]
$$

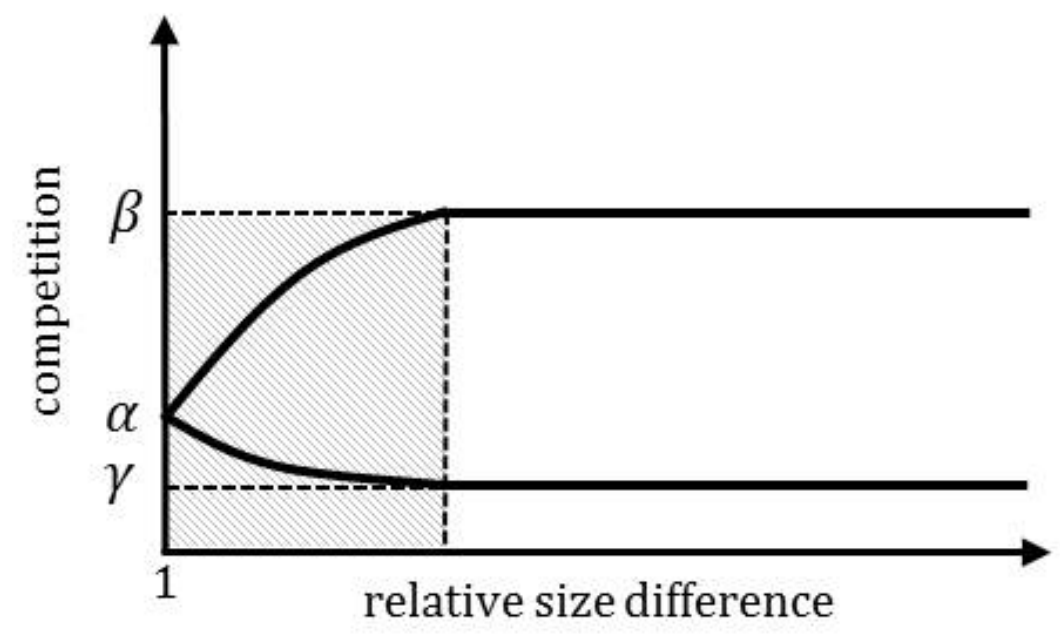

Figure 2: Theoretical relationships between competition parameters and the relative size difference between the two strata. Our model for the 2-strata stand, which assumes constant values for competition parameters, cannot be interpreted for low relative size differences. 


\subsection{One-stratum (1-stratum) stands}

Let us now define a stand with only one spatially homogeneous stratum. This stand has the same basal area $2 G$ and the same mean tree basal area $g$ as the 2-strata stand (Fig. 3). The mean tree basal area $g$ of the trees thus equals:

$$
g=\frac{2 g_{l} g_{u}}{g_{l}+g_{u}} .
$$

For this spatially homogeneous 1-stratum stand, the basal area growth is defined as:

$$
\Delta G_{2}=2 G \frac{\Delta g}{g}=2 G g^{b-1} e^{-c g} e^{-\alpha 2 G} .
$$

We also define a stand characterised by two spatially segregated strata of half an hectare each and with basal area per hectare $2 G$ (Fig. 3): the first stratum contains trees with size $g_{l}$ and the other stratum trees with size $g_{u}$. For this spatially heterogeneous 1-stratum stand, the basal area growth equals:

$$
\Delta G_{3}=\frac{1}{2} 2 G\left(\frac{\Delta g_{l}}{g_{l}}+\frac{\Delta g_{u}}{g_{u}}\right)=G\left[a g_{l}^{b-1} e^{-c g_{l}} e^{-\alpha 2 G}+a g_{u}^{b-1} e^{-c g_{u}} e^{-\alpha 2 G}\right] .
$$

These two stands reflect two different situations. For the first stand, we compare a 2-strata stand with a perfectly homogeneous 1-stratum stand with trees of intermediate size, which is usually what people investigate when they analyse the effect of tree size inequality on productivity. For the second stand, we compare a 2-strata stand with equivalent but spatially segregated strata. This spatially heterogeneous 1-stratum stand and the 2-strata stand have the same size inequality. By comparing the results obtained for these two 1-stratum stands we can assess the direct effect of the ontogenetic growth on the 2 -strata stand productivity. 

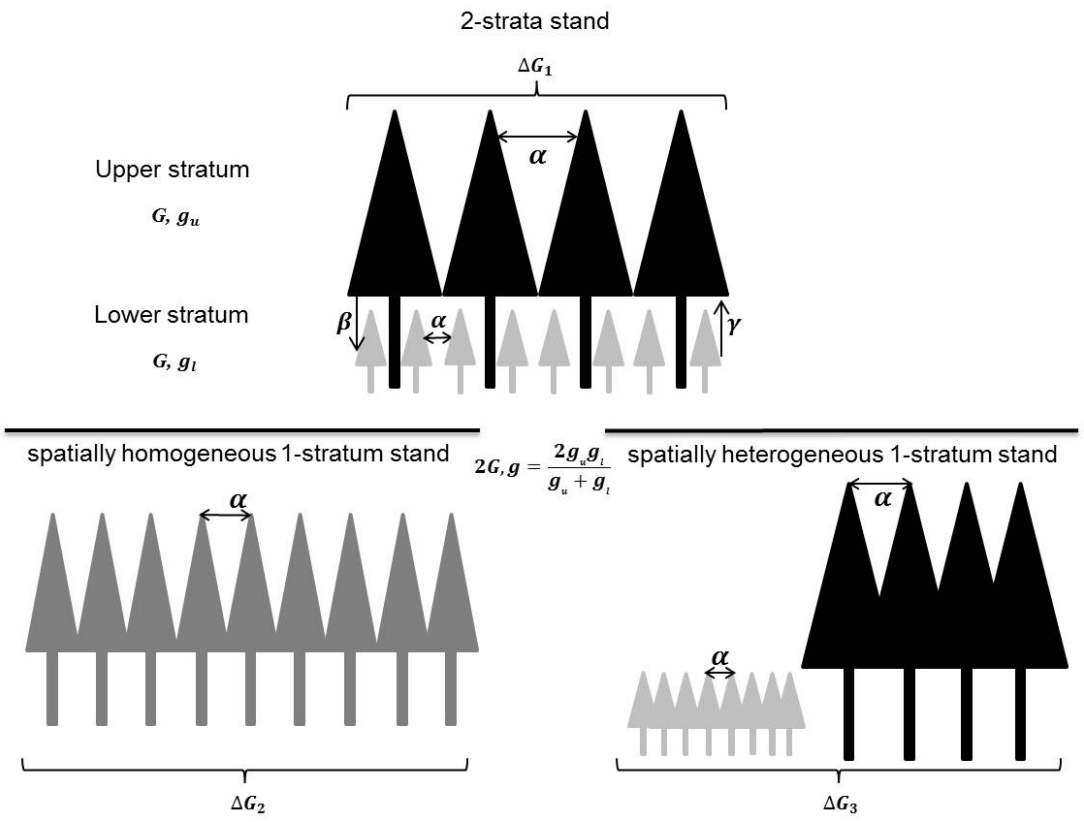

Figure 3: Comparison of the basal area growth of the 2-strata stand with two 1-stratum stands: a spatially homogeneous 1-stratum stand and a spatially heterogeneous 1-stratum stand. The 2-strata stand and the two 1-stratum stands have the same total basal area per hectare $2 G$ and the same quadratic mean diameter $g$, two key parameters of productivity (stocking and development stage). Parameters $\alpha, \beta, \gamma$ characterise competitive interactions between trees of the same stratum or between trees of the two strata. $\beta^{\prime}=\beta-\alpha$ represents the intensity of size-asymmetric competition of the upper stratum. $\gamma^{\prime}=\alpha-\gamma$ represents the type of size-asymmetric competition of the lower stratum. $\gamma^{\prime}=\alpha$ : absolute size-asymmetric competition; $0<\gamma^{\prime}<\alpha$ : partial size-asymmetric competition; $\gamma^{\prime}=0$ : relative size-asymmetric competition.

\subsection{Comparing the 2-strata stand with 1-stratum stands}

The objective is now to compare the basal area growth of the 2-strata stand with the two 1-stratum stands. One way consists in calculating the ratio of their basal area growths (which are assumed to be strictly positive), which gives respectively:

$$
\begin{gathered}
\frac{\Delta G_{1}}{\Delta G_{2}}=\frac{1}{2}\left[\left(\frac{g_{l}}{g}\right)^{b-1} e^{-c\left(g_{l}-g\right)} e^{-(\beta-\alpha) G}+\left(\frac{g_{u}}{g}\right)^{b-1} e^{-c\left(g_{u}-g\right)} e^{-(\gamma-\alpha) G}\right], \\
\frac{\Delta G_{1}}{\Delta G_{3}}=\frac{g_{l}^{b-1} e^{-c g_{l}} e^{-(\beta-\alpha) G}+g_{u}^{b-1} e^{-c g_{u}} e^{-(\gamma-\alpha) G}}{g_{l}^{b-1} e^{-c g_{l}}+g_{u}^{b-1} e^{-c g_{u}}} .
\end{gathered}
$$


When these ratios are strictly greater than 1, the 2-strata stand has higher growth than the 1-stratum stands, which leads to the following inequalities:

$$
\begin{gathered}
\frac{1}{2}\left[\left(\frac{g_{l}}{g}\right)^{b-1} e^{-c\left(g_{l}-g\right)} e^{-\beta^{\prime} G}+\left(\frac{g_{u}}{g}\right)^{b-1} e^{-c\left(g_{u}-g\right)} e^{\gamma^{\prime} G}\right]>1, \\
\frac{g_{l}^{b-1} e^{-c g_{l}} e^{-\beta^{\prime} G}+g_{u}^{b-1} e^{-c g_{u}} e^{\gamma^{\prime} G}}{g_{l}^{b-1} e^{-c g_{l}}+g_{u}^{b-1} e^{-c g_{u}}}>1,
\end{gathered}
$$

with $\beta^{\prime}=\beta-\alpha\left(\beta^{\prime}>0\right)$ and $\gamma^{\prime}=\alpha-\gamma\left(0 \leq \gamma^{\prime} \leq \alpha\right)$.

The parameter $\beta^{\prime}$ represents the intensity of size-asymmetric competition of the upper stratum. Higher values of $\beta^{\prime}$ lead to a greater detrimental effect of dominant trees on dominated trees. The parameter $\gamma^{\prime}$ represents the type of size-asymmetric competition of the lower stratum. When $\gamma^{\prime}=\alpha$, we obtain "absolute size-asymmetric competition" (Rasmussen and Weiner, 2017) (also called perfect one-sided competition (Kohyama, 1993)). In this case, trees in the lower stratum have no effect on trees in the upper stratum. When $0<\gamma^{\prime}<\alpha$, we obtain "partial size-asymmetric competition" (Rasmussen and Weiner, 2017). Here, trees in the lower stratum have less effect on dominant trees than on trees in the same stratum. We call the specific case $\gamma^{\prime}=0$ "relative size-asymmetric competition". This corresponds to the classic hypothesis that a dominated tree has the same competitive effect $\left(e^{-\alpha g_{l}}\right)$ on all trees in the stand. It is important to note that contrary to the definitions of the type of size-asymmetric competition used in previous publications (see Rasmussen and Weiner, 2017) here we distinguish between the size-asymmetric competition of the upper and lower strata.

In the next sections we investigate under which conditions inequalities (1) and (2) are achieved. For each 1-stratum stand, we first study the specific case of size-independent growth $(b=c=0)$. Then we analyse the case of positive size-dependent growth $(b>0$ and $c=0)$. Finally, we address the general case $(c>0$ and $b>0)$. To represent the relative difference in tree sizes between the two strata, we define $x$ as the ratio of their 
basal areas:

$$
x:=\frac{g_{u}}{g_{l}} .
$$

171

Throughout the article, we will consider $x \geq 2$ (see explanation above). To characterize size inequality, we use the coefficient of variation of tree basal areas (e.g. Danescu et al., 2016) in the 2-strata stand. We have:

$$
C V=\frac{x-1}{2 \sqrt{x}}
$$

For numerical applications, we extracted from the literature values obtained for $b$ and $c$ (Pokharel and Dech, 2012; Cordonnier and Kunstler, 2015; Wykoff, 1990; Monserud and Sterba, 1996; Schröder et al., 2002). We will thus consider $0.3 \leq b \leq 1.2$ and $0 \leq c \leq 4$. For competition parameters we chose arbitrary but realistic values of $\beta^{\prime}$ and $\gamma^{\prime}: 0.001 \leq \beta^{\prime} \leq 0.01,0 \leq \gamma^{\prime} \leq 0.01$. In numerical examples we also provide $C V$ with a minimum value of $0.35(x=2)$.

\section{Results}

3.1. Size-independent growth $(b=c=0)$

We assume here that basal area growth is independent of tree basal area. In this case the inequalities (1) and (2) are equivalent and become:

$$
\frac{g}{g_{l}} e^{-\beta^{\prime} G}+\frac{g}{g_{u}} e^{\gamma^{\prime} G}>2
$$

As $\frac{g}{g_{l}}=\frac{2 x}{1+x}$ and $\frac{g}{g_{u}}=\frac{2}{1+x}$, we obtain the following inequality:

$$
x\left(e^{-\beta^{\prime} G}-1\right)+e^{\gamma^{\prime} G}>1 .
$$


For the sake of readability, let us define the function $f$ as follows:

$$
f(x)=x\left(e^{-\beta^{\prime} G}-1\right)+e^{\gamma^{\prime} G}-1 .
$$

We have $f^{\prime}(x)<0$ and $\lim _{x \rightarrow+\infty} f(x)=-\infty(f$ is a linear function of $x)$. The value of the function $f$ at the minimum value of $x$ considered (2) is given by:

$$
f(2)=2 e^{-\beta^{\prime} G}+e^{\gamma^{\prime} G}-3,
$$

which is positive when:

$$
\gamma^{\prime}>\frac{\ln \left(3-2 e^{-\beta^{\prime} G}\right)}{G}=\gamma_{0}^{\prime} .
$$

We thus obtain two cases:

- if $\gamma^{\prime}>\gamma_{0}^{\prime}, f$ is positive and then negative. It crosses 0 at $x=x_{0}=\frac{e^{\gamma^{\prime} G}-1}{1-e^{-\beta^{\prime} G}}$;

- if $\gamma^{\prime}<\gamma_{0}^{\prime}, f$ is negative and the 2-strata stand is always less productive than the 1-stratum stands.

When $\gamma^{\prime}=0$ (relative size-asymmetric competition) the 2-strata stand cannot have higher productivity than the 1-stratum stands. Inequality (4) also leads to the conclusion that $\alpha$ and $\gamma^{\prime}$ must be high enough to allow for higher productivity of the 2 -strata stand. In other words, a higher intensity of size-asymmetric competition $\left(\beta^{\prime}\right)$ must be compensated by a higher value of intra-stratum competition $(\alpha)$ and a reduction of the effect of the lower stratum on the upper stratum (higher value of $\gamma^{\prime}$; highest value obtained for absolute size-asymmetric competition). The equations for $\gamma_{0}^{\prime}$ and $x_{0}$ also indicate that higher values of $G$ are beneficial to the 2 -strata stand $\left(\lim _{G \rightarrow+\infty} \gamma_{0}^{\prime}=0\right.$, $\lim _{G \rightarrow 0} \gamma_{0}^{\prime}=\beta^{\prime}, x_{0}$ is an increasing function of $\left.G\right)$. Fig. 4 gives numerical examples. Note that we are representing the variation of the growth ratio as a function of $C V$ and 


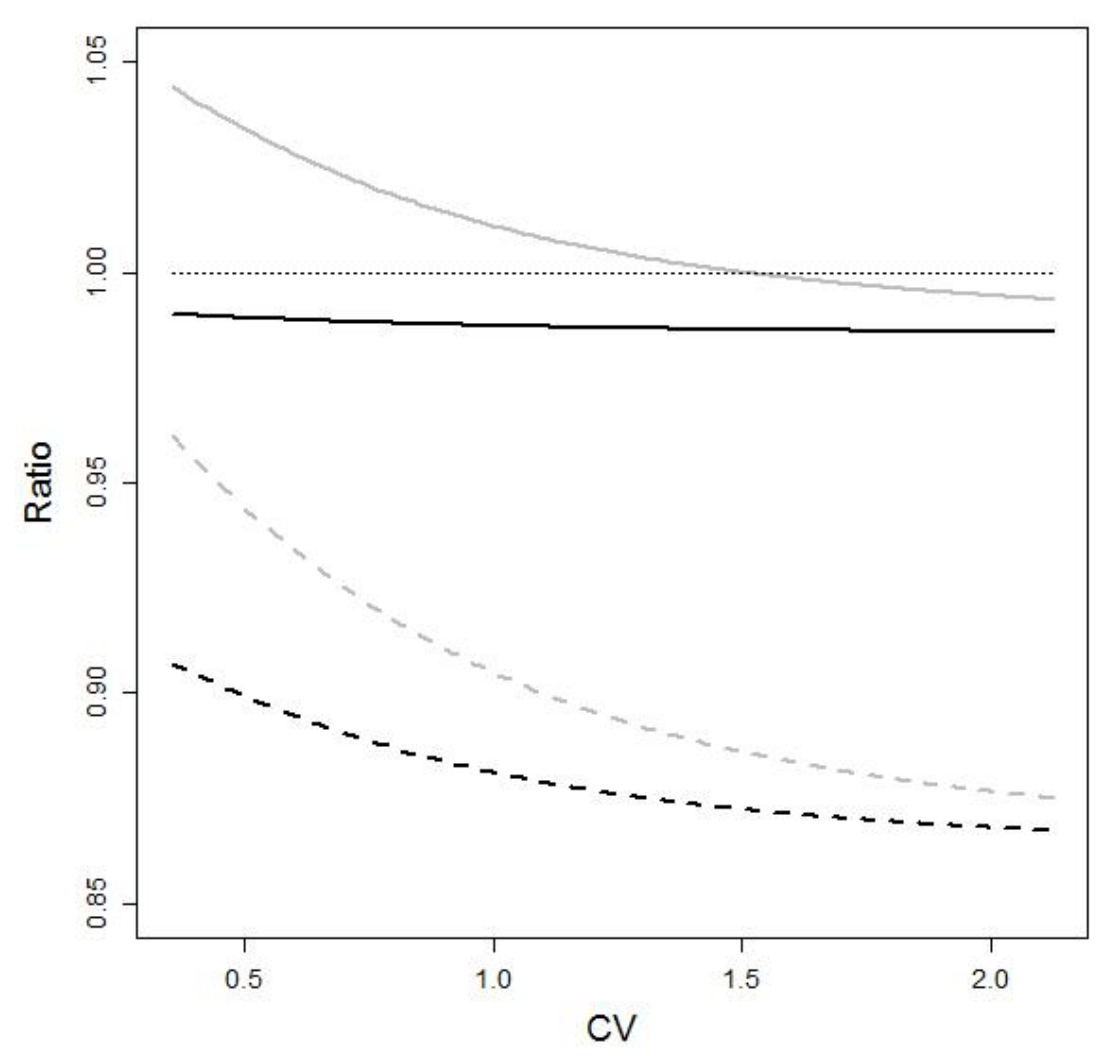

Figure 4: Growth ratio between the 2-strata stand and 1-stratum stands for the size-independent growth model $(b=c=0)$ as a function of the coefficient of variation $C V$. Black: $\gamma^{\prime}=0$, grey: $\gamma^{\prime}=0.01$, solid line: $\beta^{\prime}=0.001$, dashed line: $\beta^{\prime}=0.01 . G=15$.

not $x$ as $C V$ is the variable the most frequently used in field studies (this will be the case for all figures.)

3.2. Positive size-growth relationship $(b>0, c=0)$

3.2.1. Spatially homogeneous 1-stratum stand

In this case, basal area growth increases monotonically with size and inequality (1) becomes:

$$
\left(\frac{g_{l}}{g}\right)^{b-1} e^{-\beta^{\prime} G}+\left(\frac{g_{u}}{g}\right)^{b-1} e^{\gamma^{\prime} G}>2 .
$$


This inequality can be written:

$$
g(x)=(2 x)^{1-b} e^{-\beta^{\prime} G}+2^{1-b} e^{\gamma^{\prime} G}-2(1+x)^{1-b}>0 .
$$

For $b<1$ we have $\lim _{x \rightarrow+\infty} g(x)=-\infty$ and for $b>1$ we have $\lim _{x \rightarrow+\infty} g(x)=$ $2^{1-b} e^{\gamma^{\prime} G}$. We can derive $g$ :

$$
g^{\prime}(x)=2^{1-b}(b-1) x^{-b}\left(\left(\frac{2 x}{1+x}\right)^{b}-e^{-\beta^{\prime} G}\right),
$$

whose sign depends on $b-1$. If $b>1, g^{\prime}(x)$ is positive for all $x$ and $g$ is an increasing function of $x$. If $b<1, g^{\prime}(x)$ is negative and the function $g$ is a decreasing function of $x$. For the value of $g(2)$, we obtain equation (3) multiplied by $2^{1-b}$. The inequality determining if $g(2)$ is greater than 0 is the same as inequality (4).

We thus have four cases (Fig. 5):

- $b<1$ and $\gamma^{\prime}<\gamma_{0}^{\prime}$ : $g$ is a decreasing function of $x$ and is always negative. The 2-strata stand has a lower productivity than the spatially homogeneous 1-stratum stand.

- $b<1$ and $\gamma^{\prime}>\gamma_{0}^{\prime}: g$ is a decreasing function of $x$, first positive and then negative. There exists a $x_{1}$ so that $g\left(x_{1}\right)=0$.

- $b>1$ and $\gamma^{\prime}>\gamma_{0}^{\prime}: g$ is an increasing function of $x$ and is always positive. The 2strata stand is always more productive than the spatially homogeneous 1-stratum stand.

- $b>1$ and $\gamma^{\prime}<\gamma_{0}^{\prime}: g$ is an increasing function of $x$, first negative then positive. There exists a $x_{1}$ so that $g\left(x_{1}\right)=0$. 

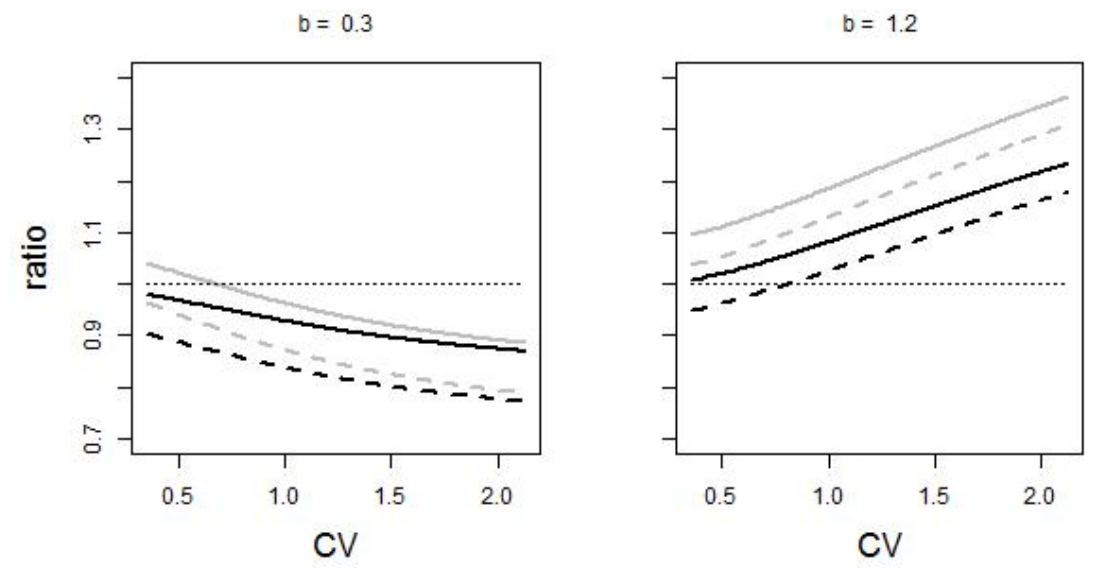

Figure 5: Growth ratio between the 2-strata stand and the spatially homogeneous 1-stratum stand as a function of the coefficient of variation $C V$ for $b>0$ and $c=0$. Black: $\gamma^{\prime}=0$, grey: $\gamma^{\prime}=0.01$, solid line: $\beta^{\prime}=0.001$, dashed line: $\beta^{\prime}=0.01 . G=15, g=0.1$.

\subsubsection{Spatially heterogeneous 1-stratum stand}

As for the spatially homogeneous 1-stratum stand we obtain four different cases that are represented on Fig. 6. The main difference is that the magnitude of the effect of the $C V$ on the growth ratio is much smaller for the spatially heterogeneous 1-stratum stand than for the spatially homogeneous 1-stratum stand (Fig. 6 vs Fig 5).

The mathematical derivation of the four cases is very close to the one of the spatially homogeneous 1-stratum stand.

Inequality (2) becomes:

$$
\frac{g_{l}^{b-1} e^{-\beta^{\prime} G}+g_{u}^{b-1} e^{\gamma^{\prime} G}}{g_{l}^{b-1}+g_{u}^{b-1}} .
$$

This can be written:

$$
h(x)=e^{-\beta^{\prime} G}-1+x^{b-1}\left(e^{\gamma^{\prime} G}-1\right)>0 .
$$

We have:

$$
h^{\prime}(x)=(b-1) x^{b-2}\left(e^{\gamma^{\prime} G}-1\right),
$$


whose sign depends on $b-1$. We also obtain equation (3) and inequality (4) for $h(2)$ and $\gamma^{\prime}$ respectively.

We thus obtain four cases (Fig. 6):

- $b<1$ and $\gamma^{\prime}<\gamma_{0}^{\prime}$ : $h$ is negative and is a decreasing function of $x$. The 2-strata stand has a lower productivity than the spatially heterogeneous 1-stratum stand.

- $b<1$ and $\gamma^{\prime}>\gamma_{0}^{\prime}$ : $h$ is a decreasing function of $x$ and crosses 0 at $x=$ $\left(\frac{1-e^{-\beta^{\prime} G}}{e^{\gamma^{\prime} G-1}}\right)^{\frac{1}{b-1}}=x_{0}^{\frac{1}{1-b}}$.

- $b>1$ and $\gamma^{\prime}>\gamma_{0}^{\prime}: h$ is positive and is an increasing function of $x$. The 2-strata stand is always more productive than the spatially heterogeneous 1-stratum stand.

- $b>1$ and $\gamma^{\prime}<\gamma_{0}^{\prime}: h$ is an increasing function of $x$ and crosses $x$ at $x=x_{0}^{\frac{1}{1-b}}$.
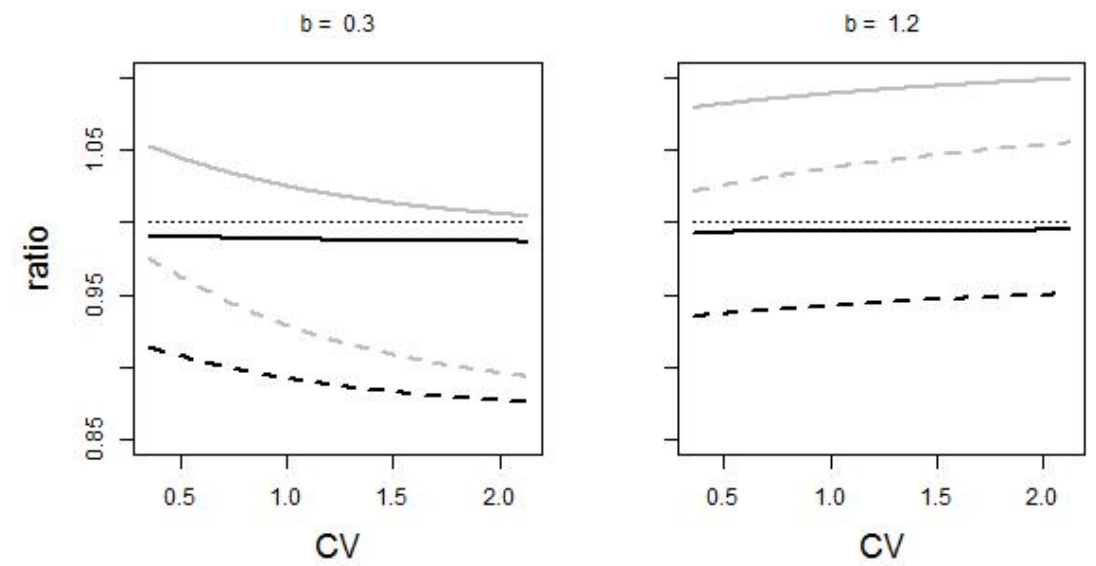

Figure 6: Growth ratio between the 2-strata stand and the spatially heterogeneous 1-stratum stand as a function of the coefficient of variation $C V$ for $b>0$ and $c=0$. Black: $\gamma^{\prime}=0$, grey: $\gamma^{\prime}=0.01$, solid line: $\beta^{\prime}=0.001$, dashed line: $\beta^{\prime}=0.01 . G=15, g=0.1$.

\subsection{General case $(b>0, c>0)$}

\subsubsection{Spatially homogeneous 1-stratum stand}

This case cannot be addressed analytically. In Fig. 7, we provide examples of relationships between the size inequality and the growth ratio between the two stands 

non-monotonous relationships when $b>1$.
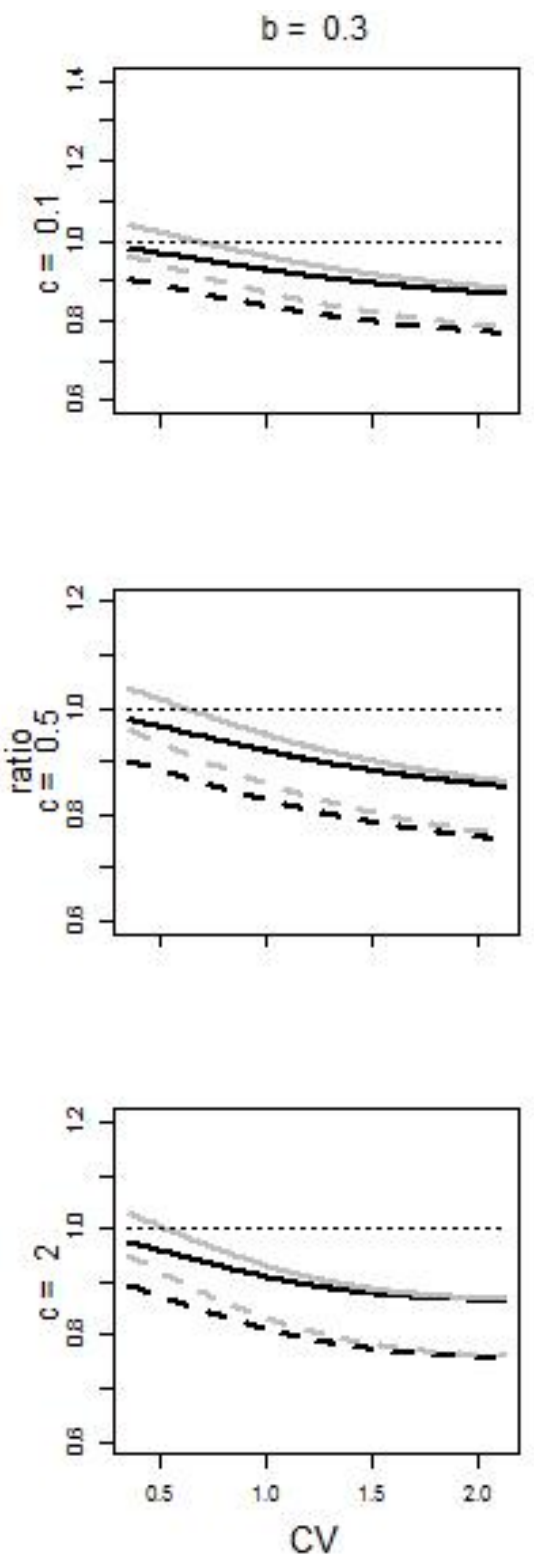
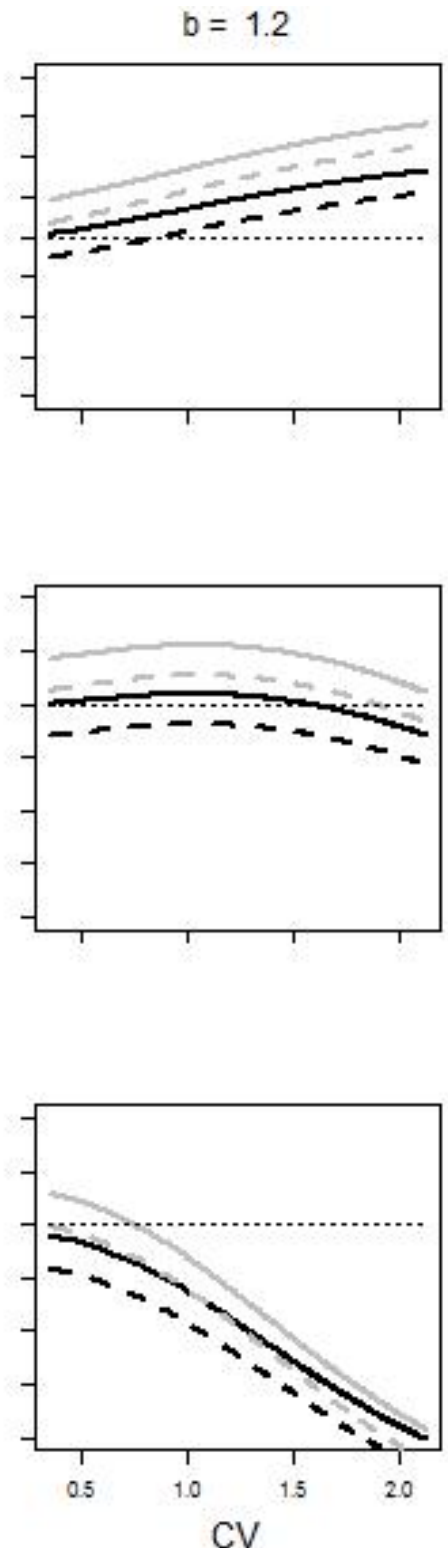

Figure 7: Growth ratio between the 2-strata stand and the spatially homogeneous 1-stratum stand as a function of the coefficient of variation $C V$ for $b>0$ and $c>0$. Black: $\gamma^{\prime}=0$, grey: $\gamma^{\prime}=0.01$, solid line: $\beta^{\prime}=0.001$, dashed line: $\beta^{\prime}=0.01 . G=15, g=0.1$. 


\subsubsection{Spatially heterogeneous 1-stratum stand}

Because this case removes the direct effect of ontogeny we can address the determinant of the growth ratio analytically (see below). We found the same kind of relationships but the magnitude of the effect of $C V$ was much smaller than in the spatially homogeneous 1-stratum stand (Fig. 8 vs. Fig. 7). The analytic derivation is similar to the one of the positive size-growth model $(b>0, c=0)$. We obtain the following inequality:

$$
\frac{e^{-\beta^{\prime} G}+x^{b-1} e^{-c g_{l}(x-1)} e^{\gamma^{\prime} G}}{1+x^{b-1} e^{-c g_{l}(x-1)}}>1
$$

which is equivalent to:

$$
k(x)=e^{-\beta^{\prime} G}-1+x^{b-1} e^{-c g_{l}(x-1)}\left(e^{\gamma^{\prime} G}-1\right)>0 .
$$

We have:

$$
k^{\prime}(x)=\left(e^{\gamma^{\prime} G}-1\right) x^{b-2} e^{-c g_{l}(x-1)}\left((b-1)-c g_{l} x\right),
$$

whose sign depends on $l(x)=(b-1)-c g_{l} x$. We define:

$$
x_{l}=\frac{b-1}{c g_{l}} .
$$

If $b<1, l(x)<0$ then $k$ is a decreasing function of $x$. If $b>1$ : for $1<x<x_{l}$, $k$ is an increasing function of $x$ and for $x>x_{l}>1, k$ is a decreasing function of $x$. We also obtain equation (3) and inequality (4) for $k(2)$ and $\gamma^{\prime}$ respectively. We have $\lim _{x \rightarrow+\infty} f(x)=e^{-\beta^{\prime} G}-1<0$.

We have thus the following cases (Fig. 8):

- $b<1$ or $\left(b>1\right.$ and $\left.x_{l}<1\right), k$ is a decreasing function of $x$.

- $\gamma^{\prime}<\gamma_{0}^{\prime}$ : $k$ is always negative and the 2-strata stand has a lower productivity 
than the spatially heterogeneous 1-stratum stand.

- $\gamma^{\prime}>\gamma_{0}^{\prime}: k$ is positive and then negative. There exists a $x_{2}$ so that $f\left(x_{2}\right)=0$.

- $b>1$ and $x_{l}>1: k$ increases then decreases.

- $\gamma^{\prime}<\gamma_{0}^{\prime}$ and $k\left(x_{l}\right)>0: k$ is negative, then positive and then negative again. It crosses 0 twice.

- $\gamma^{\prime}<\gamma_{0}^{\prime}$ and $k\left(x_{l}\right)<0: k$ is always negative and the 2-strata stand has a lower productivity than the spatially heterogeneous 1-stratum stand.

- $\gamma^{\prime}>\gamma_{0}^{\prime}: k$ is positive and then negative. There exists a $x_{2}$ so that $f\left(x_{2}\right)=0$.

\subsubsection{Effects of basal area and mean tree basal area on the growth ratio}

We investigated the effects of the basal area $G\left(m h a^{-1}\right)$ and the mean tree basal area $g(m)$ on the growth ratio in the case of the spatially homogeneous 1-stratum stand. We especially looked at whether a change in $G$ or $g$ increases or decreases the range of $C V$ where the growth ratio is greater than 1 . To do that we analysed the effect of $G$ and $g$ on the value of $C V$ at which the growth ratio equals $1\left(C V_{1}\right)$. When the growth ratio is a an increasing (decreasing) function of $C V$, an increase in $C V_{1}$ decreases (increases) the range of $C V$ with a growth ratio greater than 1 (favourable to the 2-strata stand). Fig. 9 shows that when the size inequality-productivity relationship is negative (e.g. $b=0.3$ ) an increase in basal area increases the range of $C V$ favourable to the 2-strata stand. For the mean tree basal area, we found a negative effect on the range of $C V$ favourable to the 2-strata stand (Fig. 10).

\section{Discussion}

With our simple model, we have shown that the 2-strata stand can be either more productive or less productive than the 1-stratum stands depending on the ontogenetic 

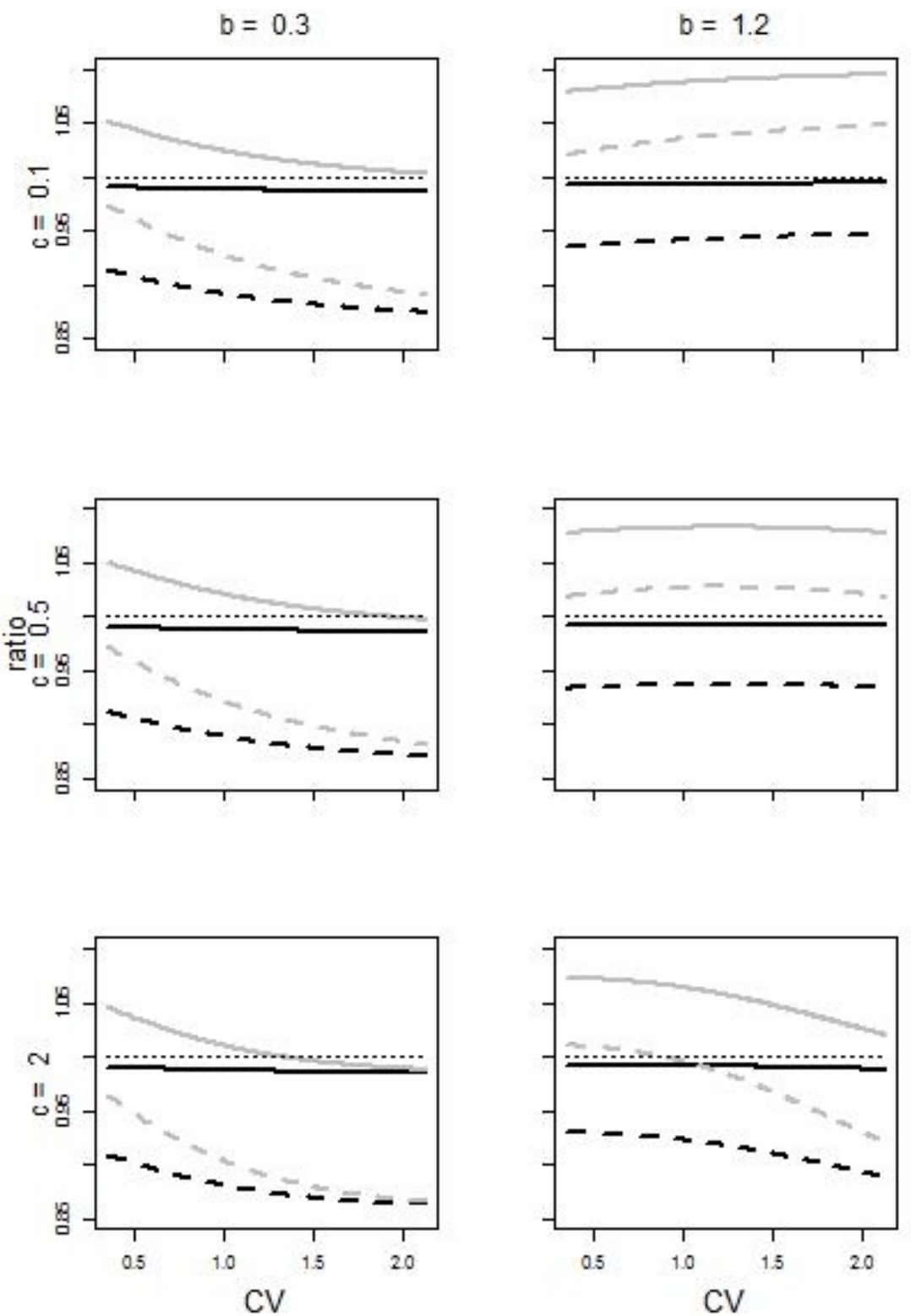

Figure 8: Growth ratio between the 2-strata stand and the spatially heterogeneous 1-stratum stand as a function of the coefficient of variation $C V$ for $b>0$ and $c>0$. Black: $\gamma^{\prime}=0$, grey: $\gamma^{\prime}=0.01$, solid line: $\beta^{\prime}=0.001$, dashed line: $\beta^{\prime}=0.01$. $G=15, g=0.1$.

and competitive effects and the characteristic of the stand. We have also shown that, contrary to the classical hypothesis of a competition effect, the main driver of the effect of size inequality on productivity is the shape of the ontogenetic growth function. These 

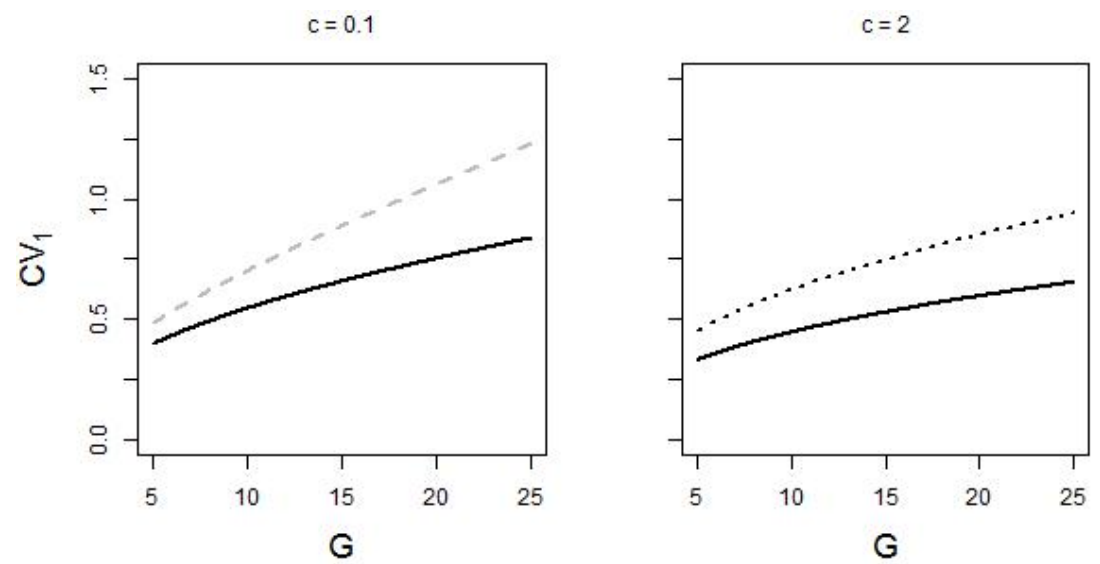

Figure 9: Coefficient of variation $C V_{1}$ when the growth ratio equals 1 as a function of the basal area $G\left(m^{2} h a^{-1}\right)$ (spatially homogeneous 1-stratum stand; $b>0$ and $c>0$ ). Black: negative relationship between size inequality and productivity ratio. Grey: positive relationship between size inequality and productivity ratio. Solid line: $\beta^{\prime}=0.001, \gamma^{\prime}=0.01, b=0.3$. Dashed line: $\beta^{\prime}=0.01, \gamma^{\prime}=0, b=1.2$. Dotted line: $\beta^{\prime}=0.001, \gamma^{\prime}=0.01, b=1.2 . g=0.1$.
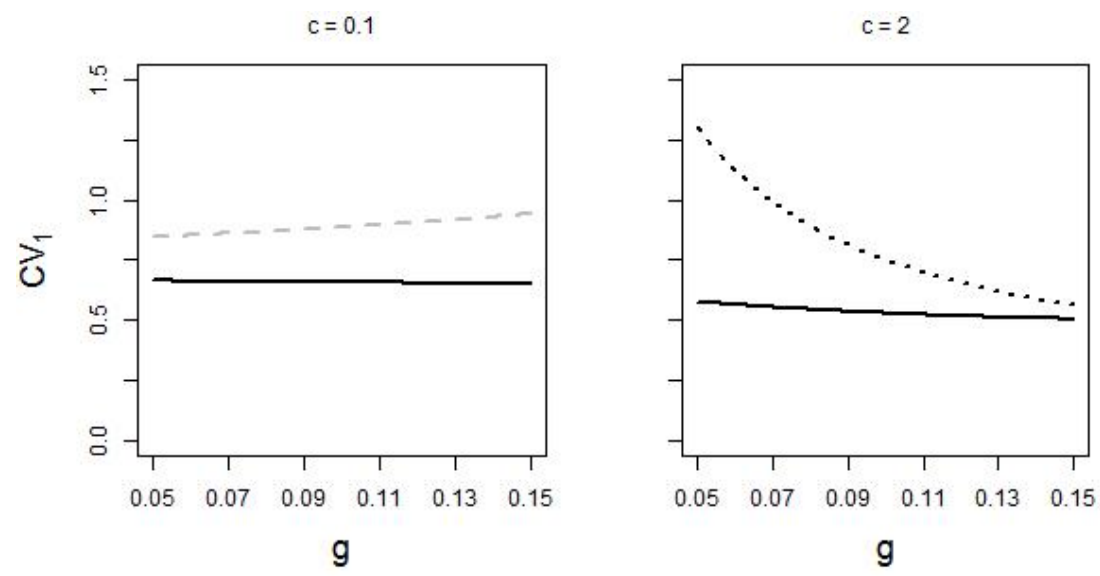

Figure 10: Coefficient of variation $C V_{1}$ when the growth ratio equals 1 as a function of the mean tree basal area $g\left(m^{2}\right)$ (spatially homogeneous 1-stratum stand; $b>0$ and $c>0$ ). Black: negative relationship between size inequality and productivity ratio. Grey: relationship between size inequality and productivity ratio. Solid line: $\beta^{\prime}=0.001, \gamma^{\prime}=0.01, b=0.3$. Dashed line: $\beta^{\prime}=0.01, \gamma^{\prime}=0$, $b=1.2$. Dotted line: $\beta^{\prime}=0.001, \gamma^{\prime}=0.01, b=1.2 . G=15$.

results help to better understand the diversity of patterns reported in the literature concerning the size inequality-productivity relationship. 


\subsection{Ontogenetic effects}

Our results show that the ontogenetic growth function has a huge impact on the conclusions drawn on higher or lower productivity of 2-strata stands. For instance, we found that depending on the values of $b$, one can find higher productivity $(b>1)$ or lower productivity of the 2 -strata stands $(b<1)$ for the same values of competition parameters. In the literature, $b$ has been shown to take values ranging roughly from 0.3 (Wykoff, 1990; Monserud and Sterba, 1996; Schröder et al., 2002) to 1.2 (Pokharel and Dech, 2012), depending on the species. Although less frequent, values above 1 have been reported in different parts of the world: in North America (Pokharel and Dech, 2012; Wykoff, 1990) and in Europe (Cordonnier and Kunstler, 2015). The parameter $c$, which was significant for most species in empirical studies (see Monserud and Sterba (1996) for some exceptions but in this case the parameter $b$ is inferior to 1 ), had a negative effect. Moreover, the effect of total basal area on the 2-strata stand depends also on the ontogenetic growth function (parameter $b$ ). This indicates that one cannot conclude on the effects of tree interactions based on size inequality-productivity patterns without controlling for species ontogenetic growth. This also indicates that conditions to obtain more productive 2-strata stands should be quite limited ( $b$ usually inferior to 1 and $c>0$ when $b>1)$.

\subsection{Competition effects}

For competition parameters, the higher productivity of the 2-strata stand appears easier to achieve when the intensity of size-asymmetric competition $\left(\beta^{\prime}\right)$ is low and the type of size-asymmetric competition tends towards absolute size-asymmetric competition $\left(\gamma^{\prime}\right.$ close to $\left.\alpha\right)$. This corresponds to the case where inter-strata competition (represented by $\beta^{\prime}-\gamma^{\prime}$ ) is reduced compared to intra-stratum competition $(\alpha)$. Absolute size-asymmetric competition (also called perfect one-sided competition) has been considered in theoretical modelling studies either to simplify analytical results or to fo- 
cus on competition for light (e.g. Kohyama and Takada, 2012). The results reported herein indicate that this choice can have a major influence on conclusions about stand productivity in size-structured forest ecosystems. Other ecological studies assumed relative size-asymmetric competition $\left(\gamma^{\prime}=0\right.$, Kunstler et al. (2011)). In the present study, this appears to be detrimental to the 2-strata stands because it increases inter-strata competition. Our study shows that modelling choices on competition types can lead to different conclusions on the relative advantage of 1-stratum or 2-strata stands as regards current productivity.

\subsection{Species characteristics and site effects}

The intensity of asymmetric competition (here $\beta^{\prime}$ ) has been reported to be usually high in forest ecosystems (Cordonnier and Kunstler, 2015; Pretzsch and Biber, 2010; Onoda et al., 2016). Actually, in plant communities, both competition for light and competition for soil resources (usually considered as size-symmetric competition) occur at the same time (Schwinning and Weiner, 1998) with intensities varying depending on species characteristics and the ecological situations considered. Using plots in New Zealand forests and controlling for basal area, Coomes and Allen (2007) showed that competition for light was high at low elevation, decreased with elevation and became comparable to competition for soil resources (that does not vary with elevation) at high elevation. This pattern has also been highlighted by Pretzsch and Biber (2010) who found higher size-asymmetric competition on fertile sites for three common species in Europe. Regarding our modelling framework, this would potentially lead to a higher occurrence of more productive 2-strata stands compared to 1-stratum stands in low productive sites. However, a recent study (Sun et al., 2018) found more pronounced negative effects of size inequality in low quality sites in Sassafras tzumu plantations in central China. According to our results, this pattern could be explained by a joint change in the intensity of size asymmetric competition $\left(\beta^{\prime}\right)$ and the type of competition 
$\left(\gamma^{\prime}\right)$ with site quality. This points out the need to better quantify the effect of ecological conditions on size-symmetric and size-asymmetric competitions and its consequence for size-productivity relationships.

Our results also indicate that 2-strata stands with species that are highly sensitive to light competition (e.g. Quercus robur, Pinus sylvestris, Pinus contorta) should be less productive than 1-stratum stands. This result has been found for Eucalyptus species (Soares et al., 2016). However, Bourdier et al. (2016) found no impact of species shade tolerance on the effect of size inequality on stand productivity. This result could come from positive co-variations between canopy light interception and shade tolerance (Canham et al., 1994; Messier et al., 1998), which here would lead to comparable values of parameter $\beta^{\prime}$ among species.

We found that for $b<1$ the total basal area should have a positive effect on the range of size-inequality values favourable to the 2-strata stand. For the mean tree basal area, we found a negative effect. These results confirm the need to control for these two key variables (stand density and mean tree size) when one wants to compare the productivity of stands having different size structures.

\subsection{The size inequality-productivity relationship}

The effect of size inequality measured here by the coefficient of variation of tree sizes in the 2-strata stand has contrasting effects on productivity depending on growth and competition parameters. This result is of major importance because it could partly explain why some studies highlight negative relationships between tree size diversity and productivity (e.g. Bourdier et al., 2016; Soares et al., 2016; Sun et al., 2018) while others emphasise positive ones (e.g. Danescu et al., 2016), although positive ones have only been found in mixed forests (once the species richness effect controlled). In the present study, size inequality is usually detrimental to productivity except when $b>1$ and $c$ is low. We also found cases where the relationship between size inequality and productivity 
is non-monotonous (e.g. Fig. 7 and 8). These patterns indicate that attention must be paid to covering large gradients of size diversity, which is not necessarily easy to achieve in field studies. The patterns obtained for the two 1-stratum stands were very similar, indicating that the direct effect of ontogenetic growth does not really impact the sizeinequality-productivity relationship qualitatively. However, for the same competition and growth parameters, variations of the growth ratio were much higher for the spatially homogeneous 1-stratum stand than for the spatially heterogeneous 1-stratum stand. This result highlights a major quantitative effect of ontogenetic growth on the size inequality-productivity relationship.

\subsection{Model limitations}

Our conclusions must be taken with caution given our simplistic approach and some important simplifications made. For instance, parameter $\gamma^{\prime}$ might depend on size inequality $x$ (we expect $\gamma^{\prime}$ to increase with $x$; Fig. 1) because trees with a substantial difference in size might interact differently for resource acquisition than trees with similar sizes. This phenomenon could emerge in simulations with models having detailed algorithms on competition for light (Courbaud et al., 2015). According to our results, this would lead to more positive relationships between size inequality and productivity, a result that has been obtained in some, but not all, simulation studies (Silva Pedro et al., 2017). In addition, these results do not capture canopy plasticity and thus potential packing effects induced by this plasticity (Ishii et al., 2013). This phenomenon can be translated into a lower increase of $\beta^{\prime}$ with $x$, which here again is favourable to more productive 2-strata stands.

Our model is static and does not deal with long-term effects of stand stratification on productivity. Nevertheless, it has the potential to be used to study the temporal size inequality-productivity relationship because the ratio between the relative growth rates of the two strata determines the change of $C V$ with time. However, to accurately 
represent the long-term change in the $C V$, this would require modelling mortality and recruitment rates. Finally, the extension of our model to stands having more than two strata is not straightforward.

Despite these limitations, our model can provide interesting insights on the expected effects of species, local conditions and stand structures on the size inequality-productivity relationship and thus contribute to discussions on forest management system options in different ecological conditions.

\subsection{The stand structure effect}

Our approach relies on evaluating the productivity of a 2-strata stand with varying levels of size inequality. Once the basal area $G$, the mean tree basal area $g$ and the size inequality $C V$ are specified, several stand structures can still be defined, which requires to build on another assumption. Here we assumed that basal area $G$ is the same in the two strata, which results in lower number of trees in the upper stratum than in the lower stratum. This is a reasonable approximation, based on the wide spread observation of $\mathrm{J}$ shaped size distributions in natural forests ecosystems. As shown in Fig. 4, this leads to a negative effect of size inequality on the growth ratio even without ontogenetic growth. This "stand structure effect" per se could explain why we conclude on a higher prevalence of negative relationships between size inequality and productivity. However, other assumptions regarding stand structure are also possible. As a consequence, we investigated another specific case where the number of trees is the same in the two strata (equal size distribution). Although the main conclusions still hold, we found some slight differences (not shown). For $b<1$ but close to 1 , we can obtain positive relationships between size inequality and productivity for a combination of low values of $\gamma^{\prime}$ and high values of $\beta^{\prime}$ and $g$. We can also observe negative relationships for $b>1$ ( $b$ close to 1 ) when $\gamma^{\prime}, \beta^{\prime}$ and $g$ are high. These results indicate that our conclusions appear quite robust to the way we distribute the number of trees or the basal area between the two 
strata. It however also shows that the choice is not totally neutral and can induce some

differences for size inequality-productivity patterns, which requires further analyses.

\subsection{Conclusions}

The strength of our 2-strata model is to show that even with a simple representation of growth and competition we found a wide range of patterns of size inequalityproductivity relationships. Overall, our results indicate that negative size inequalityproductivity relationships in monospecific stands may be the rule and that positive relationships may emerge when size-asymmetric competition is weak, size-asymmetric competition is quasi-absolute and growth-size relationship is concave-shaped. We hope this will motivate researchers to develop mechanistic approaches to better identify conditions that lead to higher productivity of highly size-structured stands.

\section{Acknowledgements}

This study was funded by the BGF program (project DISTIMACC, Ecofor 2014-23) and supported by the GIS-Coop (E 12/2016). This work was also partially funded by the Chair "Modélisation Mathématique et Biodiversité" of VEOLIA-Ecole PolytechniqueMNHN-F.X. LESSEM is part of Labex OSUG@2020 (ANR10 LABX56).

\section{References}

Binkley, D., Stape, J. L., Bauerle, W. L., Ryan, M. G., 2010. Explaining growth of individual trees: Light interception and efficiency of light use by Eucalyptus at four sites in Brazil. For. Ecol. Manage. 259, 1704?1713.

Bohn, F. J., Huth, A., 2017. The importance of forest structure to biodiversityproductivity relationships. R. Soc. Open Sci. 4. 
Bontemps, J. D., Bouriaud, O., 2014. Predictive approaches to forest site productivity: Recent trends, challenges and future perspectives. Forestry 87, 109-128.

Bourdier, T., Cordonnier, T., Kunstler, G., Piedallu, C., Lagarrigues, G., Courbaud, B., 2016. Tree size inequality reduces forest productivity: An analysis combining inventory data for ten European species and a light competition model. PLoS ONE 11.

Brang, P., Spathelf, P., Larsen, J. B., Bauhus, J., Bončina, A., Chauvin, C., Drössler, L., Garca-Gemes, C., Heiri, C., Kerr, G., Lexer, M. J., Mason, B., Mohren, F., Mhlethaler, U., Nocentini, S., Svoboda, M., 2014. Suitability of close-to-nature silviculture for adapting temperate European forests to climate change. Forestry 87, 492-503.

Canham, C. D., Finzi, A., Pacala, S. W., Burbank, D. H., 1994. Causes and consequences of resource heterogeneity in forests: interspecific variation in light transmission by canopy trees. Can. J. For. Res. 24, 337-349.

Cardinale, B. J., Duffy, J. E., Gonzalez, A., Hooper, D. U., Perrings, C., Venail, P., Narwani, A., Mace, G. M., Tilman, D., Wardle, D. A., Kinzig, A. P., Daily, G. C., Loreau, M., Grace, J. B., Larigauderie, A., Srivastava, D. S., Naeem, S., 2012. Biodiversity loss and its impact on humanity. Nature 486, 59-67.

Connell, J. H., 1983. On the prevalence and relative importance of interspecific competition: evidence from field experiments. Am. Nat. 122, 661-683.

Coomes, D.A., Allen, R.B., 2007. Effects of size, competition and altitude on tree growth. J. Ecol 95, 1084-1097.

Cordonnier, T., Kunstler, G., 2015. The Gini index brings asymmetric competition to light. Perspect. Plant Ecol. Evol. Syst. 17, 107-115. 
Courbaud, B., Lafond, V., Lagarrigues, G., Vieilledent, G., Cordonnier, T., Jabot, F., de Coligny, F., 2015. Applying ecological model evaludation: Lessons learned with the forest dynamics model Samsara2. Ecol. Model. 314, 1-14.

Damgaard, C., Weiner, J., 2000. Describing inequality in plant size or fecundity. Ecology $81,1139-1142$.

Dănescu, A., Albrecht, A. T., Bauhus, J., 2016. Structural diversity promotes productivity of mixed, uneven-aged forests in southwestern Germany. Oecologia 182, 319-333.

Forrester, D. I., Bauhus, J., 2016. A review of processes behind diversity - productivity relationships in forests. Curr. Forestry Rep. 2, 45-61.

Ishii, H., Azuma, W., Nabeshima, E., 2013. The need for a canopy perspective to understand the importance of phenotypic plasticity for promoting species coexistence and light-use complementarity in forest ecosystems. Ecol. Res. 28, 191-198.

Kern, C. C., Burton, J. I., Raymond, P., D'Amato, A., Keeton, W. S., Royo, A. A., Walters, M. B., Webster, C. R., Willis, J.L., 2017. Challenges facing gap-based silviculture and possible solutions for mesic northern forests in North America. Forestry 90, 4-17.

Kohyama, T., 1993. Size-structured tree populations in gap-dynamic forest-The forest architecture hypothesis for the stable coexistence of species. J. Ecol. 81, 131-143.

Kohyama, T. S., Takada, T., 2012. One-sided competition for light promotes coexistence of forest trees that share the same adult height. J. Ecol. 10, 1501-1511.

Kunstler, G., Albert, C., Courbaud, B., Lavergne, S., Thuiller, W., Vieilledent, G., Zimmermann, N.E., Coomes, D.A. Effects of competition on tree radial growth vary in importance but not in intensity along climatic gradients. J. Ecol. 99, 300-312. 
Leites, L. P., Robinson, A. P., Crookston, N. L., 2009. Accuracy and equivalence testing of crown ratio models and assessment of their impact on diameter growth and basal area increment predictions of two variants of the Forest Vegetation Simulator. Can. J. For. Res. 39, 655-665.

Liang, J., Buongiorno, J., Monserud, R. A., Kruger, E. L., Zhou, M., 2007. Effects of diversity of tree species and size on forest basal area growth, recruitment, and mortality. For. Ecol. Manag. 243, 116-127.

Long, J. N., Shaw, J. D., 2010. The influence of compositional and structural diversity on forest productivity. Forestry 83, 121-128.

McElhinny, C., Gibbons, P., Brack, C., Bauhus, J., 2005. Forest and woodland stand structural complexity: its definition and measurement. For. Ecol. Manag. 218, 1-24.

Messier, C., Parent, S., Bergeron, Y., 1998. Effects of overstory and understory vegetation on the understory light environment in mixed boreal forests. J. Veg. Sci. 9, 511-520.

Messier, C., Puettmann, K., Chazdon, R., Andersson, K. P., Angers, V. A., Brotons, L., Filotas, E., Tittler, R., Parrott, L., Levin, S. A., 2015. From management to stewardship: viewing forests as complex adaptive systems in an uncertain world. Conserv. Lett. 8, 368-377.

Monserud, R. A., Sterba, H., 1996. A basal area increment model for individual trees growing in uneven-aged forest stands in Austria. For. Ecol. Manag. 80, 57-80.

Onoda, Y., Saluga, J. B., Akutsu, K., Aiba, S., Yahara, T., Anten, N. P., Canham, C., 2014. Trade-off between light interception efficiency and light use efficiency: implications for species coexistence in one-sided light competition. J. Ecol. 102, 167-175. 
Pretzsch, H., Biber, P., 2010. Size-symmetric versus size-asymmetric competition and growth partitioning among trees in forest stands along an ecological gradient in central Europe. Can. J. For. Res. 40, 370-384.

Pokharel, B., Dech, J., 2012. Mixed-effects basal area increment models for tree species in the boreal forest of Ontario, Canada using an ecological land classification approach to incorporate site effects. Forestry 85, 255-270.

Rasmussen, C. R., Weiner, J., 2017. Modelling the effect of size-asymmetric competition on size inequality: Simple models with two plants. Ecol. Model. 343, 101-108.

Rohner, B., Waldner, P., Lischke, H., Feretti, M., Thrig, E., 2018 Predicting individualtree growth of central European tree species as a function of site, stand, management, nutrient, and climate effects. Eur. J. For. Res. 137, 29-44.

Ryan, M. G., Stape, J. L., Binkley, D., Fonseca, S., Loos, R. A., Takahashi, E. N., Silva, C. R., Silva, S. R., Hakamada, R. E., Ferreira, J. M., Lima, A. M. N., Gava, J. L., Leite, F. P., Andrade, H. B., Alves, J. M., Silva, G. G. C., 2010. Factors controlling Eucalyptus productivity: How water availability and stand structure alter production and carbon allocation. For. Ecol. Manag. 259, 1695-1703.

Schröder, J., Soalleiro, R. R., Alonso, G. V., 2002. An age-independent basal area increment model for maritime pine trees in northwestern Spain. For. Ecol. Manag. $157,55-64$.

Schwinning, S., Weiner, J., 1998. Mechanisms determining the degree of asymmetry in competition among plants. Oecologia 113, 447-455.

Silva Pedro, M., Rammer, W., Seidl, R., 2017. Disentangling the effects of compositional and structural diversity on forest productivity. J. Veg. Sci. 28, 649-658. 
Soares, A. A. V., Leite, H. G., Souza, A. L., Silva, S. R., Loureno, H. M., Forrester, D. I., 2016. Increasing stand structural heterogeneity reduces productivity in Brazilian Eucalyptus monoclonal stands. For. Ecol. Manag. 373, 26-32.

Stephenson, N. L., Das, A. J., Condit, R., Russo, S. E., Baker, P. J., Beckman, N. G., Coomes, D. A., Lines, E. R., Morris, W. K., Rger, N., lvarez, E., Blundo, C., Bunyavejchewin, S., Chuyong, G., Davies, S. J., Duque, ., Ewango, C. N., Flores, O., Franklin, J. F., Grau, H. R., Hao, Z., Harmon, M. E., Hubbell, S. P., Kenfack, D., Lin, Y., Makana, J. R., Malizia, A., Malizia, L. R., Pabst, R. J., Pongpattananurak, N., Su, S. H., Sun, I. F., Tan, S., Thomas, D., Van Mantgem, P. J., Wang, X., Wiser, S. K., Zavala, M. A., 2014. Rate of tree carbon accumulation increases continuously with tree size. Nature 507, 90-93.

Sun, H., Diao, S., Liu, R., Forrester, D., Soares, A., Saito, D., Dong, R., Jiang, J., 2018. Relationship between size inequality and stand productivity is modified by self-thinning, age, site and planting density in Sassafras tzumu plantations in central China. Forest Ecology and Management 422, 199-206.

Vilà, M., Carrillo-Gaviln, A., Vayreda, J., Bugmann, H., Fridman, J., Grodzki, W., Haase, J., Kunstler, G., Schelhaas, M. J., Trasobares, A., 2013. Disentangling biodiversity and climatic determinants of wood production. PLoS ONE 8.

Weiner, J., 1990. Asymmetric competition in plant populations. Trends Ecol. Evol. 5, 360-364.

West, G. B., Brown, J. H., Enquist, B. J., 2001. A general model for ontogenetic growth. Nature 413, 628-631.

Wykoff, W. R., 1990. A basal area increment model for individual conifers in the northern rocky mountains. For. Sci. 36, 1077-1104. 
Zeller, L., Liang, J., Pretzsch, H., 2018. Tree species richness enhances stand productivity while stand structure can have opposite effects, based on forest inventory data from Germany and the United States of America. For. Ecosyst. 5, 4. 